\title{
Role of Estrogen Receptors in Male Reproductive Physiology
}

\section{Richard R. LEE* ${ }^{*}$, Karen P. PHILLIPS 2}

1 Student, University of Ottawa, Canada

2 Professor, University of Ottawa, Canada

*Auteur(e) correspondant | Corresponding author: richardlee066@gmail.com

\section{Résumé :}

(traduction)

\section{Mots-clés :}

\section{Abstract:}

Keywords:
Les récepteurs des œestrogènes canoniques $(E R \alpha / \beta)$ ont un mécanisme d'action génomique, fonctionnant comme des facteurs de transcription nucléaires pour les gènes œstrogéno-dépendantes. Les récepteurs œstrogéniques sont bien établis au sein de l'appareil reproducteur mâle où l'œstrogène joue un rôle essentiel au niveau de la fertilité masculine.

La caractérisation récente du nouveau récepteur œstrogénique couplé à une protéine G GPR30 (également connue sous GPER1), reposant sur la capacité des voies de signalisation intracellulaires non génomiques de transduire des signaux œstrogéniques, nécessite un réexamen du rôle des récepteurs des œstrogènes au niveau de la reproduction masculine. En outre, l'affinité des œstrogènes environnementaux (xéno-œstrogènes) pour les sous-types de récepteurs œestrogéniques pourra fournir de renseignements supplémentaires concernant les effets reproductifs de ces produits chimiques sur la fertilité des hommes.

Nous examinons ici la structure et les fonctions de chaque récepteur ostrogène dans le cadre de la reproduction masculine, en portant une attention particulière aux conséquences reproductives de l'exposition aux xéno-œstrogènes.

GPR30, GPER1, xeno-œestrogène, signalisation, reproduction mâle

Canonical estrogen receptors $(E R \alpha / \beta)$ have a genomic mechanism of action, functioning as nuclear transcription factors for estrogen-dependent genes. Estrogen receptors are well established within the male reproductive tract with estrogen playing an essential role for male fertility.

The recent characterization of novel G-protein coupled estrogen receptor GPR3o (alternatively known as GPER1), depending on non-genomic intracellular signaling pathways to transduce estrogenic signals, requires a re-examination of the roles of estrogen receptors in male reproduction. Further, the affinity of environmental estrogens (xenoestrogens) for estrogen receptor subtypes may provide additional understanding of the reproductive effects of these chemicals on male fertility.

Here we review the structure and functions of each estrogen receptor within the context of male reproduction, with special consideration of the reproductive implications of xenoestrogen exposure.

GPR30, GPER1, male reproduction, signalling, xenoestrogen 


\section{Traditional Estrogen Receptors}

Traditionally, estrogen receptors are known as liganddependent transcription factors which have been found to be located within the confines of the cell's membrane and bind the steroidal hormone estrogen (Hess et al., 1997). These conventional nuclear steroidal receptors have been identified as ER $\alpha$ and Estrogen Receptor- $\beta$ (ER $\beta)$, where $\operatorname{ER} \beta$ was discovered less than 20 years ago in 1996. These receptors are produced by two separate and distinct genes found on separate chromosomes and are also not isoforms of each other (O'Donnell, Robertson, Jones, \& Simpson, 2001).

A main difference between these two receptors involves their individual expression within specific tissues. ER $\alpha$ is the major species expressed in the uterus, liver, adipose tissue, skeletal muscle, pituitary, and hypothalamus. Conversely, $\mathrm{ER} \beta$ is the dominant form in ovary and prostate tissues, and regions of the brain such as the limbic system, cerebellum, and cerebral cortex (O'Donnell et al., 2001; Shughrue \& Mechenthaler, 2000).

The structure of both receptors involves six functional domains denoted A-F (O'Donnell et al., 2001). Among these domains, the A/B domain is the least homologous between the two, and contains the activation function $1(\mathrm{AF}-1)$ region-one of the two areas critical for the transactivation function, or increased rate of gene expression, of the members of the ligand-activated nuclear receptor family. The $\mathrm{C}$ domain of these estrogen receptors is the most highly conserved region, implicating its importance in functional value, and it contains the DNA binding domain with zincfinger motifs (O’Donnell et al., 2001). Ligands bind specifically within the $\mathrm{E}$ domain, which is moderately conserved, and although each receptor (ER $\alpha$ and ER $\beta$ ) binds estradiol (17 $\beta$-estradiol or E2) with similar affinity, the relative binding affinity of other ligands displays discrepancies (Kuiper, Carlsson, Grandien, Enmark, Häggblad, Nilsson, et al., 1997). Within the C'-terminus of the $\mathrm{E}$ domain lays the other critical area for transactivation function (AF-2), and this place is denoted as the F domain (O'Donnell et al., 2001).

The signal transduction of ER $\alpha$ involves the action of AF-1 and the E2-dependent AF-2. AF-2 has been demonstrated in several studies to be controlled by ligand binding activity, specifically E2. In contrast, AF-1 possesses three major phosphorlyation sites at serines 104 and/or 106, serine 118, and serine 167; and since mutations of these sites reduces transactivation by ER $\alpha$, it is suggested that phosphorylation plays an important role in regulating AF-1 activity (Chen et al., 2002; Lannigan, 2003). Serine 118 (S118) appears to be a target for phosphorylation by cyclindependent kinase 7 (Cdk7) in response to estrogen and in a ligand-independent manner by the ERK1/2 mitogen activated protein kinases (MAPK) signal transduction pathway in response to cell surface signals. This means that $\mathrm{S} 118$ becomes phosphorylated in the presence of E2 binding, yet the experimental induction of MAPK activity leads to increased S118 phophorylation, ultimately resulting in ligand -independent transactivation by ER $\alpha$ (Chen et al., 2002). Moreover and thinking in the endogenous context without experimental intervention, perhaps an estrogen transactivation response (as a result of S118 phosphorylation) can occur via initiation of a MAPK pathway through the means of a now known cell surface estrogen receptor. This process would not involve E2 binding directly to the Era protein but rather a surface receptor which then relays secondary messages via a MAPK cascade-meaning that G-Protein Estrogen Receptor-30 (GPR-30), a surface membrane estrogen receptor, may indeed be a candidate in this described signal transduction where ERa does not need to depend on interaction with E2 for transcriptional activation.

In general however, the initiation of these activation function domains, whether through ligand-dependent or independent pathways, leads to increased association with coactivators and to secondary messages translocating ER $\alpha$ / ER $\beta$ to the nucleus-if it is not there already but rather in the cytosol. This results in the receptor-complex binding to the estrogen response element within the promoter region of the DNA via the zinc finger motifs of the $\mathrm{C}$ domain allowing gene expression to occur (Lannigan, 2003). With the investigation of ligand-independent pathways providing cross-talk routes of action in conjunction with growth factor signalling pathways, the exact molecular mechanisms of estrogen action are now known to be more complex than originally thought (O’Donnell et al., 2001).

\section{Estrogen and G-Protein Coupled Receptors}

In recent years a unique estrogen receptor located on the cell membrane has been identified. This transmembrane $\mathrm{G}$ protein-coupled receptor (GPCR) has been named GPR30 or alternatively $\mathrm{G}$ protein-coupled estrogen receptor 1 (GPER1). The role of GPR3o in estrogen signaling is still 
controversial, however proposed suggestions implicate that it is a functional estrogen receptor involved in nongenomic estrogen signaling, meaning that it can induce a rapid effect within the cell independent of nuclear receptors for estrogen (Olde \& Leeb-Lundberg, 2009). The traditional estrogen receptor transcriptional modification mechanisms require 45 minutes for new protein synthesis and it is estimated to be much longer for the alteration of cellular physiology. In contrast, it has been found that $17 \beta$ estradiol can alter neuronal firing within seconds and since this discovery, the ideology of a rapid, non-genomic capability of E2 has been applied and investigated in the context of different cellular mechanisms across different tissues (Kelly \& Wagner, 1999).

A GPCR is a seven transmembrane domain cell surface receptor associated with a $\mathrm{G}$ protein, which carries the ability to bind the guanine nucleotides GDP and GTP. The associated $\mathrm{G}$ protein is a heterotrimeric protein composed of three different subunits: $\alpha, \beta$, and $\gamma$. Upon ligand binding, an allosteric change occurs in the alpha subunit of the $\mathrm{G}$ protein $(\mathrm{G \alpha})$, giving it the ability to now bind GTP in exchange for GDP, and further activating Ga which dissociates it from its other subunits. This Ga is now able to move on to activate effector enzymes and relay a secondary messaging cascade. These second messengers most commonly involve cyclic nucleotides, inositol triphosphate (IP3) and diacylglycerol (DAG), and calcium ions $\mathrm{Ca}^{2+}$.

An early speculation of the relationship between estrogen and GPCRs involves the regulation and modulation of membrane receptors by the intracellular estrogen receptors. This viewpoint suggests estrogen receptors are able to activate adenylate cyclase production or couple to phospholipase C (PLC) beta through G-protein modification and activation, and have been demonstrated to lead to rapid increases in intracellular $\mathrm{Ca}^{2+}$ concentration as well as the formation of inositol 1,4,5-triphosphate $\left(\mathrm{IP}_{3}\right)$ and diacylglycerol (DAG) (Simoncini \& Genazzani, 2003). Some findings also suggest that ER $\alpha$ and $\mathrm{ER} \beta$ can associate with the plasma membrane and even couple with $\mathrm{G}$ proteins to activate many of the cellular cascades dependent on GPCRs (Kelly \& Wagner, 1999; Razandi, Pedram, Greene, \& Levin, 1999). This characterization of signal transduction activation proposes that estrogen can rapidly regulate multiple cellular functions through the recruitment of $\mathrm{G}$ protein pathways but also modulate longer-term processes such as gene expression, protein or DNA synthesis through nuclear -destined activated estrogen receptors (Simoncini \& Genazzani, 2003; Razandi, et al., 1999).
Another characterization regarding the interaction between estrogen and GPCRs involves the action of GPER1, which only in 2005 was classified by the International Union of Pharmacology (IUPHAR) as a membrane estrogen receptor (Olde \& Leeb-Lundberg, 2009). The rapid activation of mitogen-activated protein kinases, Erk-1 and Erk-2, by E2 were able to be shown in MCF-7 cells, which express $\mathrm{ER} \alpha$ and ER $\beta$, as well as in SKBR3 breast cancer cells, which lack both ER $\alpha$ and ER $\beta$. Thus, the estrogen-induced activation of this pathway is not necessarily dependent upon the traditional estrogen receptors alone. Furthermore, MDA-MB-231 breast cancer cells, cells that lack GPER1, are insensitive to ERK-1/-2 activation via E2 (Filardo, Quinn, Bland, \& Frackelton, 2000).

\section{GPER1: Signal Transduction}

It has been reported that GPER1 has the ability to signal via Gas proteins, and through a pertussis toxin-sensitive $\mathrm{G}$ -protein (G $\beta \gamma$ )-pertussis toxin sensitivity is a common method to discriminate whether a signaling pathway is following the Ga subunit or the G $\beta \gamma$ complex since they are both able to promote Erk-1/-2 activation, yet the G $\beta \gamma$ complex is indicated as pertussis toxin-sensitive (Olde \& LeebLundberg, 2009; Filardo et al., 2000). Activation of the Gas protein in turn activates adenylyl cyclase, increasing the cytosolic concentration of the second messenger cyclic adenosine monophosphate (cAMP), and triggering further events such as the activation of protein kinase A (PKA) leading to increased expression of cAMP-inducible genes (Olde \& Leeb-Lundberg, 2009).

The activation of the pertussis toxin-sensitive G-protein ultimately results in transactivation of the epidermal growth factor (EGF) receptor via cleavage of membranetethered heparin-bound EGF, intracellular

$\mathrm{Ca}^{2+}$ mobilization, ERK1/2 activation, and Src related tyrosine kinase activity-Src proteins are adapter proteins with domains that carry the ability to phosphorylate tyrosine residues (tyrosine kinases), an additional step of regulation for this form of cell growth (Filardo et al., 2000; Prossnitz et al., 2008). EGF receptor transactivation leads to multiple downstream events such as the activation of PLC, MAPKs, and phosphatidylinositol 3-kinases (PI3K). PLC activation generates second messengers IP3 and DAG, and the MAPKs and PI3Ks initiate numerous pathways regulating transcription factors (Prossnitz et al., 2008). Thus, the initiation of Gas proteins and $G \beta \gamma$ complexes outlines the 
beginning of the two suggested pathways of signal transduction for GPER1-leading to transcriptional activation as well as rapid signaling via the activated EGF receptor. Again, multiple routes of action may indicate developed cross-talk mechanisms for evolutionary-important pathways.

\section{GPER1: Areas of Debate}

One area of controversy around GPER 1 involves whether or not E2 acts independently of GPER1 or actually binds to it, as several laboratories have been unable to demonstrate estradiol binding or estradiol-activated signal transduction in GPER1 expressing cells (Otto et al., 2009; Otto et al., 2008). In order to establish the role of GPER1, the selective receptor agonist G-1 was developed with a higher affiity over both Era and ER $\beta$ (Olde \& Leeb-Lundberg, 2009). Otto et al. (2008) attempted in vivo experiments with estradiol and G-1 in uterus and mammary gland tissues, organs that are targets for estrogen, yet were not able to show any estrogenic effects with G-1. They continue to conclude that GPER1 is still an orphan receptor, meaning it has a similar structure to known receptors but the exact endogenous ligand has yet to be identified.

Another basis for dispute is the sub-cellular localization of GPER1. In both cells transfected and endogenously expressing GPER1, Otto et al. (2008) confirmed the receptor localized to the endoplasmic reticulum. In contrast, Filardo et al. demonstrate detectable expression of GPER1 on the surface of transfected HEK-293 cells using fluorescence-activated cell sorting, and confirming with confocal microscopy using lectin concanavalin A as a plasma membrane marker (Filardo et al., 2007). Furthermore, it has been shown by some that membrane-impermeable conjugates of E2 to bovine serum albumin (E2-BSA) have the ability to stimulate GPR30-dependent elevation of intracellular cAMP concentrations (Kelly \& Wagner, 1999; Filardo et al., 2007). Fractionation studies as well are in support of the plasma membrane as the site of GPR30 action with specific E2 binding and G protein activation (Filardo et al., 2007).

However, another proposition suggests that GPER1 is localized to the plasma membrane, yet after treatment with E2, followed by the resulting elevation of intracellular $\mathrm{Ca}^{2+}$ concentration, translocation occurs of GPER1 from the plasma membrane to the cytoplasm within one hour (Funakoshi, Yanai, Shinoda, Kawano, \& Mizukami,
2006). Altogether, the present knowledge of the novel GPER1 and its associated mechanisms of transduction, as well as the actual sub-cellular location, are in their juvenile stages, and more investigations are warranted.

\section{GPER1: Male Reproductive Tissue}

Although the actions and physiology of GPER1 within the male reproductive tissues is not well defined, the presence of GPER1 and its mRNA has been found in the mouse spermatogonial cell line GC-1 (Olde \& Leeb-Lundberg, 2009; Chimento, et al., 2010). Here the physiological role of GPER1 is suspected to work in conjunction with Era through cross-talk pathways allowing estrogen the ability to mediate transcriptional responses in the regulation of testicular function (Chimento et al., 2010). It was within this cell line that Chimento et al.(2010) demonstrated that E2 and G-1 activate the EGFR/ERK pathway (the same pathway as previously described) leading to downstream stimulation resulting in GC-1 cell growth. These findings of proliferative activity have suggested that a high level of GPR3o expression levels may predispose cells to estrogen sensitivity, altered responsiveness, and tumour proliferation (Prossnitz \& Maggioloini, 2009).

The same EGFR/ERK pathway as a result of GPER1 activation has been described within immature rat Sertoli cells. In these cells, E2 and GPER1 interaction may regulate gene expression involved with apoptosis. Thus, Lucas et al. have proposed that GPER1 may mediate actions important for Sertoli cell function and maintenance of normal testis development and homeostasis (Lucas, Royer, Siu, Lazari, \& Porto, 2010).

\section{Implications}

The implications of having multiple routes of estrogen activation, with both functional genomic and non-genomic receptors, may predispose cells to be easily responsive to estrogen-mimicking compounds from the environment. In turn, this may lead to the recent phenomenon known as endocrine disruption, referring to the ability of exogenous chemicals to interfere with hormonal systems and having the potential to negatively affect human health (Swedenborg, Rüegg, Mäkelä, \& Pongratz, 2009). 
With the increase in abundance of chemicals present in today's modern industrial society, environmental exposures to estrogen have become an area of investigation for many researchers. An example of one of these exogenous estrogenic compounds, known as xenoestrogens, is bisphenol A (BPA). BPA is used in its polymeric form as lining of food and beverage containers, baby bottles, medical tubing, and dental fillings (Swedenborg et al., 2009). This lipophilic compound leaks out of plastics when heated-a significant route of exposure-and has been shown to accumulate in human adipose tissue, plasma, urine, and breast milk (Swedenborg et al., 2009; Howdeshell et al., 2003).

Moreover, it has been shown that GPER1, like traditional estrogen receptors, are bound and activated by several endocrine-disrupting chemicals (EDCs) (Swedenborg et al., 2009). These environmental estrogens have been demonstrated to activate alternative estrogen signaling pathways to traditional ER-binding as they have been able to invoke estrogenic responses in the HEK293 ER-negative cell line stably transfected with the GPER1 receptor. The binding affinities of these xenoestrogens, including BPA, for GPER1 are similar to their affinities for ERs (a relative binding affinity of 2-3\% to that of E2). Thus, it has been indicated that non-traditional estrogenic actions via GPER1 have the characteristics and potential for endocrine disruption by a variety of xenoestrogens (Thomas \& Dong, 2006).

Therefore, due to estrogen's essential role in male reproductive health and normal fertility, the regulation of the use and exposure of these xenoestrogens is a valid avenue of policy to begin to critique; especially since the newly understood effects and mechanisms are still in their early stages where more research is warranted to precisely define them.

\section{Conclusions}

Altogether, our understanding of the physiological mechanisms of estrogen receptors has evolved to become a complex domain, especially when considering the recent findings of non-genomic signalling. Estrogenic effects have been demonstrated to be activated through both traditional ERs and the novel GPR30 membrane receptor. Signal mediation through GPR3o has been found to involve rapid cellular signalling pathways via secondary messengers, resulting in the release and transactivation of epidermal growth factor receptors (Prossnitz et al., 2008). The variety of proposed and demonstrated pathways may suggest crosstalk mechanisms, as well as specificity to tissues.

Within the tissues of the male reproductive system, estrogen's importance in development as well as in maintaining normal fertility is well recognized (Hess, 2003; Hess et al., 1997). Taking into account the various means by which estrogen has been shown and proposed to activate responses within cells, the fact that modern industrial society is continuing to allow exposure of populations to xenoestrogens on a daily basis should lead to grounds for concern. The environmental presence of exogenous estrogenic -mimicking chemicals and their ability to interact with our bodies is a recent area of research, yet has already had profound political effects such as the restrictions on BPA inclusion in the production of certain products. To further supplement these policy changes, future directions should involve delineating the specific pathways, interactions, and characteristics of endocrine disruption with regards to the estrogen receptors-novel and traditional. The transcriptional activities of GPR3o versus ERs must be clarified, and their individual contributions toward physiological effects need to be more clearly defined (Prossnitz et al., 2008). Determining the precise roles in the rapid signalling effects of estrogen and the ability of steroid receptors to exert responses via non-transcriptional mechanisms may even open new avenues of pharmacological possibilities (Simoncini \& Genazzani, 2003).

\section{References}

Chen, D., Washbrook, E., Sarwar, N., Bates, G. J., Pace, P. E., Thirunuvakkarasu, V., ... Ali, S. (2002). Phosphorylation of human estrogen receptor alpha at serine 118 by two distinct signal transduction pathways revealed by phosphorylation-specific antisera. Oncogene, 21(32), 49214931. Retrieved from http://www.nature.com/onc/ journal/v21/n32/full/1205420a.html

Chimento, A., Sirianni, R., Delalande, C., Silandre, D., Bois, C., Andò, S., ... Pezzi, V. (2010). 17 [beta]-estradiol activates rapid signaling pathways involved in rat pachytene spermatocytes apoptosis through GPR3O and ER (alpha). Molecular and Cellular Endocrinology, 320(1-2), 136-144. doi: 10.1016/j.mce.2010.01.035

Filardo, E. J., Quinn, J. A., Bland, K. I., \& Frackelton Jr, A. R. (2000). Estrogen-induced activation of Erk-1 and Erk-2 requires the $\mathrm{G}$ protein-coupled receptor homolog, GPR30, and occurs via trans-activation of the epidermal growth . 
Funakoshi, T., Yanai, A., Shinoda, K., Kawano, M. M., \& Mizukami, Y. (2006). G protein-coupled receptor 30 is an estrogen receptor in the plasma membrane. Biochemical and Biophysical Research Communications, 346(3), 904910. doi: 10.1016/j.bbrc.2006.05.191

Hess, R. A. (2003). Estrogen in the adult male reproductive tract: A review. Reproductive Biology and Endocrinology, 1(1), 52-66.

Hess, R. A., Bunick, D., Lee, K. H., Bahr, J., Taylor, J. A., Korach, K. S., \& Lubahn, D.B. (1997). A role for oestrogens in the male reproductive system. Nature, 6659, 509-511. doi: $10.1038 / 37352$

Howdeshell, K. L., Peterman, P. H., Judy, B. M., Taylor, J. A., Orazio, C. E., Ruhlen, R. L... Welshons, W.V. (2003). Bisphenol A is released from used polycarbonate animal cages into water at room temperature. Environmental Health Perspectives, 111(9), 1180. Retrieved from http:// www.ncbi.nlm.nih.gov/pmc/articles/PMC1241572/

Kelly, M. J., \& Wagner, E. J. (1999). Estrogen modulation of G-protein-coupled receptors. Trends in Endocrinology and Metabolism, 10(9), 369-374.

Kuiper, G. G. J. M., Carlsson, B., Grandien, K., Enmark, E., Häggblad, J., Nilsson, S., \& Gustafsson, J.A. (1997). Comparison of the ligand binding specificity and transcript tissue distribution of estrogen receptors $\alpha$ and $\beta$. Endocrinology, 138(3), 863-870. doi: http://dx.doi.org/10.1210/ endo.138.3.4979\#sthash.ybf8R6NW.dpuf

Lannigan, D. A. (2003). Estrogen receptor phosphorylation. Steroids, 68(1), 1-9. doi: 10.1016/Soo39-128X(02) o0110-1

Lucas, T. F. G., Royer, C., Siu, E. R., Lazari, M. F. M., \& Porto, C. S. (2010). Expression and signaling of G proteincoupled estrogen receptor 1 (GPER) in rat sertoli cells. Biology of Reproduction, 83(2), 307-317. doi: 10.1095/biolreprod.110.084160

O’Donnell, L., Robertson, K. M., Jones, M. E., \& Simpson, E. R. (2001). Estrogen and spermatogenesis. Endocrine Reviews, 22(3), 289-318. Retrieved from http:// dx.doi.org/10.1210/edrv.22.3.0431

Olde, B., \& Leeb-Lundberg, L. (2009). GPR30/GPER1: Searching for a role in estrogen physiology. Trends in Endocrinology \& Metabolism, 2O(8), 409-416. doi: 10.1016/ j.tem.2009.04.006
Otto, C., Fuchs, I., Kauselmann, G., Kern, H., Zevnik, B., Andreasen, P., et al. (2009). GPR3o does not mediate estrogenic responses in reproductive organs in mice. Biology of Reproduction, 8o(1), 34-41. doi: 10.1095/

biolreprod.108.071175

Otto, C., Rohde-Schulz, B., Schwarz, G., Fuchs, I., Klewer, M., Brittain, D., et al. (2008). G protein-coupled receptor 30 localizes to the endoplasmic reticulum and is not activated by estradiol. Endocrinology, 149(10), 4846-4856. doi: 10.1210/en.2008-0269

Prossnitz, E. R., Arterburn, J. B., Smith, H. O., Oprea, T. I., Sklar, L. A., \& Hathaway, H. J. (2008). Estrogen signaling through the transmembrane $\mathrm{G}$ protein-coupled receptor GPR30. Annual Review of Physiology, 70, 165-190. doi: 10.1146/annurev.physiol.70.113006.100518

Prossnitz, E. R., \& Maggiolini, M. (2009). Mechanisms of estrogen signaling and gene expression via GPR30. Molecular and Cellular Endocrinology, 308(1), 32 -38. doi: 10.1016/j.mce.2009.03.026

Razandi, M., Pedram, A., Greene, G. L., \& Levin, E. R. (1999). Cell membrane and nuclear estrogen receptors (ERs) originate from a single transcript: Studies of ERa and $\operatorname{Er} \beta$ expressed in Chinese hamster ovary cells. Molecular Endocrinology, 13(2), 307-319.

Shughrue, P. J., \& Merchenthaler, I. (2000). Estrogen is more than just a "sex hormone": Novel sites for estrogen action in the hippocampus and cerebral cortex. Frontiers in Neuroendocrinology, 21(1), 95-101. doi: 10.1006/ frne.1999.0190

Simoncini, T., \& Genazzani, A. R. (2003). Non-genomic actions of sex steroid hormones. European Journal of Endocrinology, 148(3), 281-292. doi: 10.1530/eje.o.1480281

Swedenborg, E., Rüegg, J., Mäkelä, S., \& Pongratz, I. (2009). Endocrine disruptive chemicals: Mechanisms of action and involvement in metabolic disorders. Journal of Molecular Endocrinology, 43(1), 1-10. doi: 10.1677/JMEo8-0132

Thomas, P., \& Dong, J. (2006). Binding and activation of the seven-transmembrane estrogen receptor GPR3o by environmental estrogens: A potential novel mechanism of endocrine disruption. The Journal of Steroid Biochemistry and Molecular Biology, 102(1-5), 175-179. doi: 10.1016/

j.jsbmb.2006.09.017 